\title{
Solubility and Conformation of High Molecular Weight Synthetic Copolypeptides in Aprotic Solvents. Dependence of the Phenyl Pendant Group on the Solubility and Conformation*
}

\author{
Masanao OYA, Toshiya ENDO, and Yasuko IIZUKA \\ Department of Industrial Chemistry College of Technology, \\ Gunma University, Kiryu-shi, Gunma 376, Japan
}

(Received November 16, 1987)

\begin{abstract}
Copolypeptides containing the phenylalanine residue were synthesized by the copolymerization of $N$-carboxy- $\alpha$-amino acid anhydrides in aprotic solvents. The influence of conformation and configuration, especially of the phenyl pendant group, on the solubility of the copolypeptide in the aprotic solvents was discussed. The copolypeptide of $\beta$-benzyl L-aspartate, $\varepsilon$ carbobenzoxy L-lysine, and L-phenylalanine in a ratio $1: 1: 1$ was more soluble in dichloroethan with less helix content than those of copolypeptide of $\beta$-benzyl L-aspartate, $\varepsilon$-carbobenzoxy Llysine, and alanine in a corresponding ratio, or copolypeptides of $\beta$-benzyl $L$-aspartate with $\varepsilon$ carbobenzoxy L-lysine in a ratio $1: 1$. The insolubility of copolypeptides of L-alanine, $\mathrm{L}$ - $\alpha$-amino $n$ butyric acid, or $\mathrm{L}-n$-leucine with $\mathrm{L}-$ phenylalanine in a ratio of $1: 1$ was similar to those of poly-Lalanine, -L- $\alpha$-amino- $n$-butyric acid, or -L- $n$-leucine. The dependence of the helix content of these copolypeptides on the phenylalanine residue was complicated. The permeability of water vapor of the copolypeptide films was not affected by the pendant group of the phenyl residue of copolypeptides.

KEY WORDS Polypeptides / Conformation / Solubility / ORD /

Permeability /
\end{abstract}

Synthetic polypeptides soluble in commercial aprotic solvents are important to cast high strength film for industrial application. Among of them, poly(L-phenylalanine) (Poly(L-Phe)) is of interest regarding physicochemical properties because of their pendant group of phenyl residue. However, this is wellknown as an insoluble polypeptide in many solvents except in a mixed solvent of dichloroacetic acid and trifluoroacetic acid at a high temperature. Polystyrene having a pendant group of phenyl methyl residue, on the contrary, is a typical soluble polymer in aprot- ic solvents. Polypeptides including the phenyl pendant group are to be insoluble in many solvents because of their strong intermolecular interaction between the phenyl groups. However, there are some cases where this does not apply.

Woodward first reported on synthesis of high molecular weight polypeptide consisting of DL-phenylalanine (DL-Phe) and L-leucine (LLeu), which is soluble in benzene near the boiling temperature, by polymerization of their $N$-carboxy-amino acid anhydride (NCA). ${ }^{1}$ Some copolypeptides containing DL-

* A part of this work was presented at the 52th National Meeting of Chemical Society Japan, Kyoto, April, 1986, Abstr. 2J38.

Abbreviations of amino acids and their derivatives in this paper are those recommended by the IUPAC-IUB Commission on Biochemical Nomenclature. 
Table I. Copolymerization of phenylalanine NCA

\begin{tabular}{|c|c|c|c|c|c|c|c|c|}
\hline \multicolumn{5}{|c|}{ Polymerization system } & \multirow{3}{*}{$\begin{array}{c}\text { ORD } \\
b_{0}\end{array}$} & \multicolumn{3}{|c|}{ Copolypeptide formed } \\
\hline \multirow[b]{2}{*}{ No. } & \multirow[b]{2}{*}{ NCAs } & \multirow[b]{2}{*}{ Ratio } & \multirow{2}{*}{$\begin{array}{l}\text { Concentra- } \\
\text { tion of } \\
\text { initial } \\
\text { monomers/ } \\
\text { mol }^{-1}\end{array}$} & \multirow{2}{*}{$\begin{array}{c}\text { Form of } \\
\text { polymerization } \\
\text { system }\end{array}$} & & \multirow{2}{*}{$\begin{array}{c}\eta_{\mathrm{sp}} / c \\
(c=0.5 \mathrm{~g} / \\
100 \mathrm{ml}) \\
\text { (in dichloro } \\
\text { acetic acid) }\end{array}$} & \multicolumn{2}{|c|}{ Film } \\
\hline & & & & & & & $\begin{array}{l}\text { Strength } \\
\left(\mathrm{kg} / \mathrm{mm}^{2}\right)\end{array}$ & $\begin{array}{l}\text { Modulus } \\
\left(\mathrm{kg} / \mathrm{mm}^{2}\right)\end{array}$ \\
\hline 1 & Phe-D-Phe & $50: 50)$ & $0.52-0.086$ & Viscous soln ${ }^{\mathrm{a}, \mathrm{b}}$ & & & & \\
\hline 2 & Phe-Ala & $(50: 50)$ & 0.272 & Insoluble & & $1.47^{\mathrm{c}}$ & & \\
\hline 3 & Phe- $n$-BA & $(50: 50)$ & 0.260 & Insoluble & & $1.47^{\mathrm{c}}$ & & \\
\hline 4 & Phe- $n$-Val & $(50: 50)$ & 0.270 & Gel B & & $1.85^{\mathrm{c}}$ & & \\
\hline 5 & Phe-n-Leu & $(50: 50)$ & 0.292 & Gel B & & $1.08^{\mathrm{c}}$ & & \\
\hline 6 & Phe-Leu & $(75: 25)$ & 0.130 & Slurry ${ }^{b, d}$ & & & & \\
\hline 7 & Phe-Leu & $(50: 50)$ & 0.130 & $\mathrm{Gel}^{\mathrm{e}}$ & -530 & $2.40^{\mathrm{c}}$ & 2.0 & 100 \\
\hline 8 & Phe-Leu & $(25: 75)$ & 0.130 & Gel (soln at $60^{\circ} \mathrm{C}$ ) & & $2.27^{\mathrm{c}}$ & 2.8 & 147 \\
\hline 9 & Phe-Leu & $(75: 25)$ & 0.135 & Precipitation $^{\mathrm{b}, \mathrm{f}}$ & & & 4.5 & 150 \\
\hline 10 & Phe-Leu & $(50: 50)$ & 0.129 & Solution (colloidal) ${ }^{\mathrm{g}}$ & -440 & $4.40^{\mathrm{c}}$ & 4.8 & 81 \\
\hline 11 & Phe-Leu & $(25: 75)$ & 0.129 & Gel (soft clear) ${ }^{\mathrm{g}}$ & +1200 & $0.609^{c}$ & & \\
\hline 12 & Phe-D-Phe-Leu & $(67: 9: 24)$ & 0.128 & Suspension ${ }^{\mathrm{b}, \mathrm{h}}$ & & & & \\
\hline 13 & Phe-D-Phe-Leu & $(47: 15: 38)$ & 0.168 & $\mathrm{Gel}^{\mathrm{b}, \mathrm{i}}$ & $\begin{array}{r}0 \\
-290^{\mathrm{i}}\end{array}$ & & & \\
\hline 14 & Phe-D-Phe-Leu & $(37: 18: 45)$ & 0.187 & $\mathrm{Gel}^{\mathrm{b}, \mathrm{j}}$ & $\begin{array}{r}-50 \\
-150^{j}\end{array}$ & & & \\
\hline 15 & Phe-D-Phe-Leu & $(23: 23: 54)$ & 0.111 & $\mathrm{Gel}^{\mathrm{b}, \mathbf{k}}$ & -400 & & & \\
\hline 16 & Phe-OBzlGlu & $(10: 90)$ & 0.10 & Solution (clear) & -570 & $0.61^{\mathrm{c}}$ & & \\
\hline 17 & Phe-OBzlGlu & $(25: 75)$ & 0.10 & Solution (clear) & -560 & $0.40^{\mathrm{c}}$ & & \\
\hline 18 & Phe-OBzlGlu & $(50: 50)$ & 0.10 & Solution (clear) & -240 & $0.52^{\mathrm{c}}$ & & \\
\hline 19 & Phe-OBzlGlu & $(75: 25)$ & 0.10 & Precipitation $^{\mathrm{b}}$ & & & & \\
\hline 20 & Phe-OBzlAsp & $(50: 50)$ & 0.117 & Solution (clear) & -320 & 0.232 & & \\
\hline 21 & Phe-OBzlAsp & $(25: 75)$ & 0.117 & Solution (clear) & -270 & 0.627 & & \\
\hline 22 & Leu-OBzlAsp & $(25: 75)$ & 0.09 & Precipitation & & 0.45 & & \\
\hline 23 & Leu-OBzlAsp & $(50: 50)$ & 0.09 & Colloidal solution & -575 & 1.10 & & \\
\hline 24 & Phe-Leu-OEtGlu & $(33: 33: 33)$ & 0.2 & Solution & -475 & & & \\
\hline 25 & Phe-OMeGlu & $(5: 95)$ & 0.17 & Colloidal solution ${ }^{k}$ & -560 & & & \\
\hline 26 & Phe-OMeGlu & $(10: 90)$ & 0.17 & Colloidal solution ${ }^{\mathbf{k}}$ & $-\mathrm{k}$ & & 3.3 & 125 \\
\hline 27 & Phe-OMeGlu & $(67: 33)$ & 0.15 & Colloidal solution $^{1}$ & -370 & & 0.43 & 25 \\
\hline 28 & Phe-OMeGlu & $(50: 50)$ & 0.17 & Colloidal solution ${ }^{k}$ & -1200 & & 3.3 & 157 \\
\hline 29 & Phe-OBzlAsp-ZLys & $(29: 23: 48)$ & 0.21 & Solution & +65 & 0.892 & & \\
\hline 30 & Ala-OBzlAsp-ZLys & $(29: 23: 48)$ & 0.21 & Solution & -580 & 0.930 & & \\
\hline 31 & Phe-SBzlCys-D-Phe & $(67: 10: 23)$ & 0.20 & Solution & -226 & & & \\
\hline 32 & Phe-SBzlCys-D-Phe & $(55: 10: 35)$ & 0.2 & Solution & -222 & & & \\
\hline 33 & OBzlAsp-Ala-Phe & $(24: 71: 5)$ & 0.19 & $\mathrm{Gel}^{1}$ & & $18.3^{\mathrm{c}}$ & & \\
\hline 34 & OBzlAsp-Ala-Phe & $(75: 20: 5)$ & 0.19 & $\mathrm{Gel}^{\mathrm{m}}$ & -420 & 1.08 & 2.76 & 33 \\
\hline 35 & DL-Phe-OMeGlu & $(10: 90)$ & 0.057 & Colloidal solution ${ }^{\mathbf{k}}$ & +8 & 1.13 & 1.5 & 77 \\
\hline 36 & DL-Phe-OMeGlu & $(25: 75)$ & 0.061 & Colloidal solution & +1400 & 0.62 & 0.4 & 46 \\
\hline
\end{tabular}

a In mixed solvents of dichloroethane (DCE) and hexane (50:50), methylene chloride and benzene.

b Polymer is insoluble in DCA and TFA.

c In trifluoroacetic acid (TFA).

d Solution by addition of two volumes of benzene to the slurry followed by heating.

e Slightly clouded; $b_{0}$ for a solution by addition of one volume of benzene to the gel.

f In benzene: A part of the polymer is soluble. $b_{0}$ cannot be measured.

${ }^{8}$ In benzene.

h Solution by addition of 2 volumes of benzene to gel. 


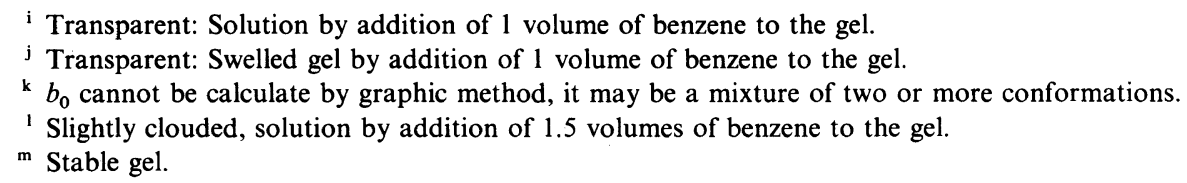

L-Phe residue as a component have been found to be soluble. ${ }^{2}$

In the previous paper we reported the relationship between the solubility of copolypeptides in aprotic solvents and pendant groups of amino acid residues. ${ }^{3}$ In this paper the dependence of solubility and conformation of copolypeptide in aprotic solvents on a pendant group, especially phenyl residue, is discussed in detail for copolypeptides consisting various component of amino acids. Differential scanning carolimetry (DSC) of copolymers was carried out to evaluate a strength of intermolecular interations between the side chains of the copolymers. The water vapour transmission rate of the coplymers was measured to evaluate hydrophobic and hydrophilic interaction between intermolecular main chains.

\section{EXPERIMENTAL}

NCAs was prepared as reported previously ${ }^{4}$ and copolymerized in dichloroethane at concentrations shown in Table I at $30^{\circ} \mathrm{C}$ for $144 \mathrm{~h}$. Optical rotatory dispersion (ORD) of polymerization solution was measured at wave lengths of 650 to $250 \mathrm{~nm}$ at about $20-25^{\circ} \mathrm{C}$ after completion of polymerization. Moffit parameters, $b_{0}$, were calculated with reference to the literature. ${ }^{5,6}$ Differential scanning calorimetry of copolymer was carried out at a sample heating rate $10^{\circ} \mathrm{C} / \mathrm{min}$ in a of SEIKO DENSI DS-10. The water vapour permeability was measuredaccording to JIS Z 0208-1976.

\section{RESULTS AND DISCUSSION}

Table I gives the results of the copolymerization of $\mathrm{L}$, or DL-Phe NCAs as components parts. Solubility of copolypeptides in the po- lymerization solution, dichloroethane or benzene, was classified with the following class: (1) solution; the polymerization system was mobility, and when the test tube containing the polymerization solution was placed on a level, the content began to flow immidiately on; (2) colloidal solution; the polymrization system was viscous, and when the test tube containing the solution was placed on a level, it flowed after a while; (3) gel; the polymerization system was gelatinous form, by the addition of more than one volume of benzene, or heating, it became the solution; (4) gel B; this was insoluble in benzene and the other aprotic solvents at bothga room and high temperatures; and (5) precipitation; polymerized polymer was obtained in the precipitation. Dried copolypeptides obtained from (1) and (2) could be easily dissolved again in dichloroethane.

Dichloroethane has no absorption band at regions $1700-1500 \mathrm{~cm}^{-1}$ and $650-410 \mathrm{~cm}^{-1}$, which includes, respectively, amide bands I-II and IV of polypeptides. Infrared spectra of the polymerization system in the suspension or opaque gel, the optical rotatory dispersion, measurement of which were observed to evaluate conformation of polypeptides in the polymerization system.

Poly(D,L-Phe) obtained by polymerization of DL-Phe NCA was soluble in methylene chloride, benzene, dichloroethane, and many other aprotic solvents, in contrast to insoluble poly(L-Phe) in almost aprotic solvents. A dichloroethane solution of poly(DL-Phe) was sicky heavy. However, the isolated polymer was insoluble in trifluoroacetic acid and dichloroacetic acid which are typical protonic solvents for many polypeptides except poly( $\mathrm{L}-$ Phe). These results indicate that the solubility 
of poly(DL-Phe) in protonic solvents such as dichloroacetic- or trifluoroacetic acid may decreased with increasing hydrophobic interaction between the intermolecular side chain of the phenyl residue. This also may indicate that the intermolecular interaction between phenyl residues are stronger than those of hydrogen bonding between amide groups. Infrared spectrum of poly(D,L-Phe) in a film showed bands at 1660 and $1650 \mathrm{~cm}^{-1}$ characteristic of $\alpha$ - and coiled conformation. ${ }^{7.8}$ Differential scanning calorimetry showed a strong exothermic peak at $336^{\circ} \mathrm{C}$ for poly(L-Phe) (Figure 1), and endthermic peaks at 296 and $320^{\circ} \mathrm{C}$, and a strong exothermic peak at $359^{\circ} \mathrm{C}$ for poly(DLPhe) (Figure 2). Poly(DL-Phe) melts without decomposition. This indicates that the intermolecular interaction between phenyl residues for poly(DL-Phe) is less than that for poly(LPhe). Consequently, the interaction of aprotic solvents with phenyl residue for poly(DL-Phe), which influences solubility in the solvents, is more stronger than that for poly(L-Phe).

Infrared spectra of the precipitated copolypeptides in system No. 2 (Ala-Phe; 50:50) gave absorption at 1655 and $1545 \mathrm{~cm}^{-1}$ of $\alpha$ conformation (Figure 3). This conformation was so stable that they did not change on replacing the polymerization solvent with other solvents. It suggests that the methyl pendant group smaller than phenyl group does not prevent intermolecular interactions between phenyl side chains. Infrared spectra of polymerization system No. 3, (Phe- $n$-BA; 50:50) including spongy copolypeptide showed the bands at 1655-1640 (Amide I), 1545-1515

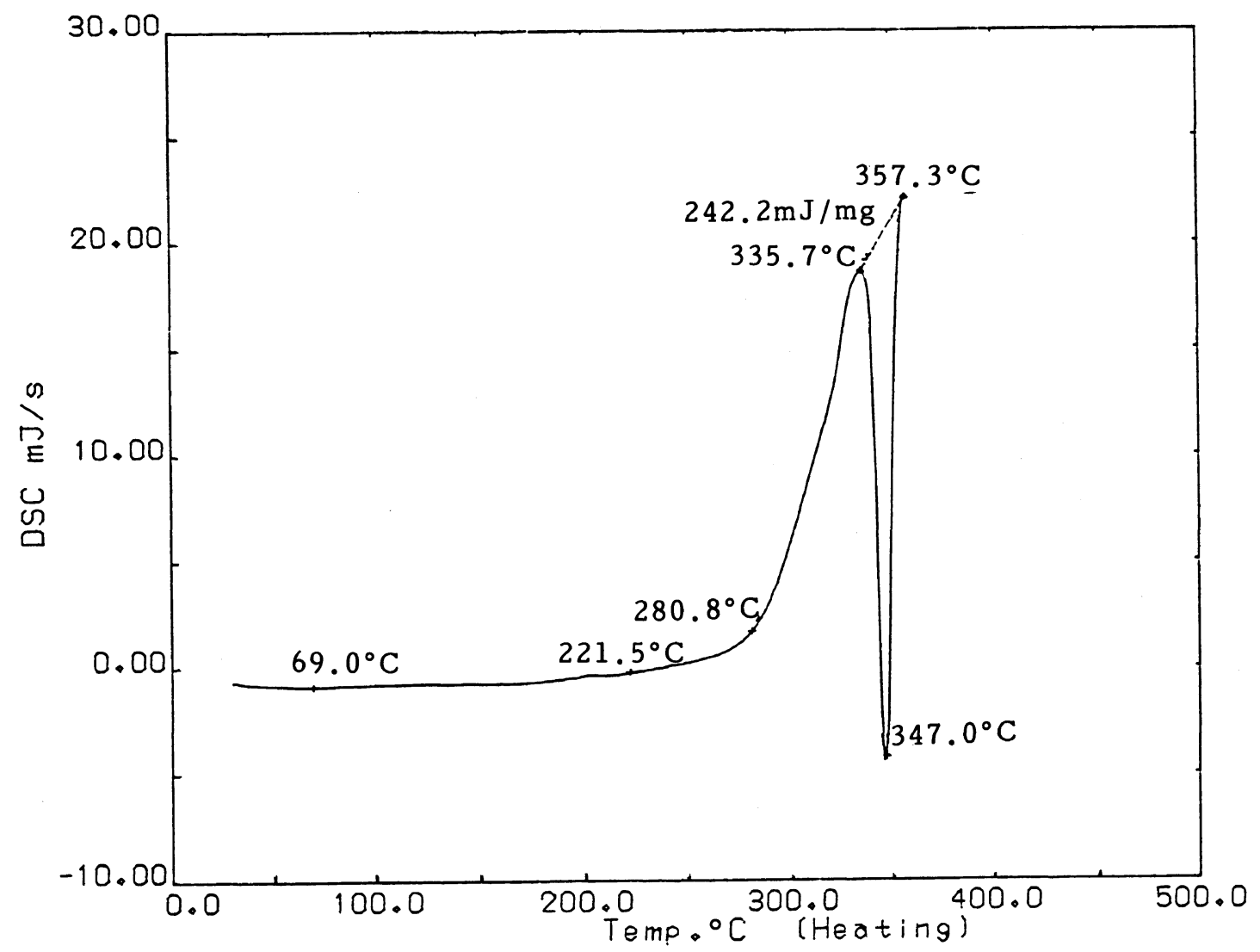

Figure 1. DSC curve of poly-L-phenylalanine. Progress rate, $5^{\circ} \mathrm{C} / \mathrm{min}$. 


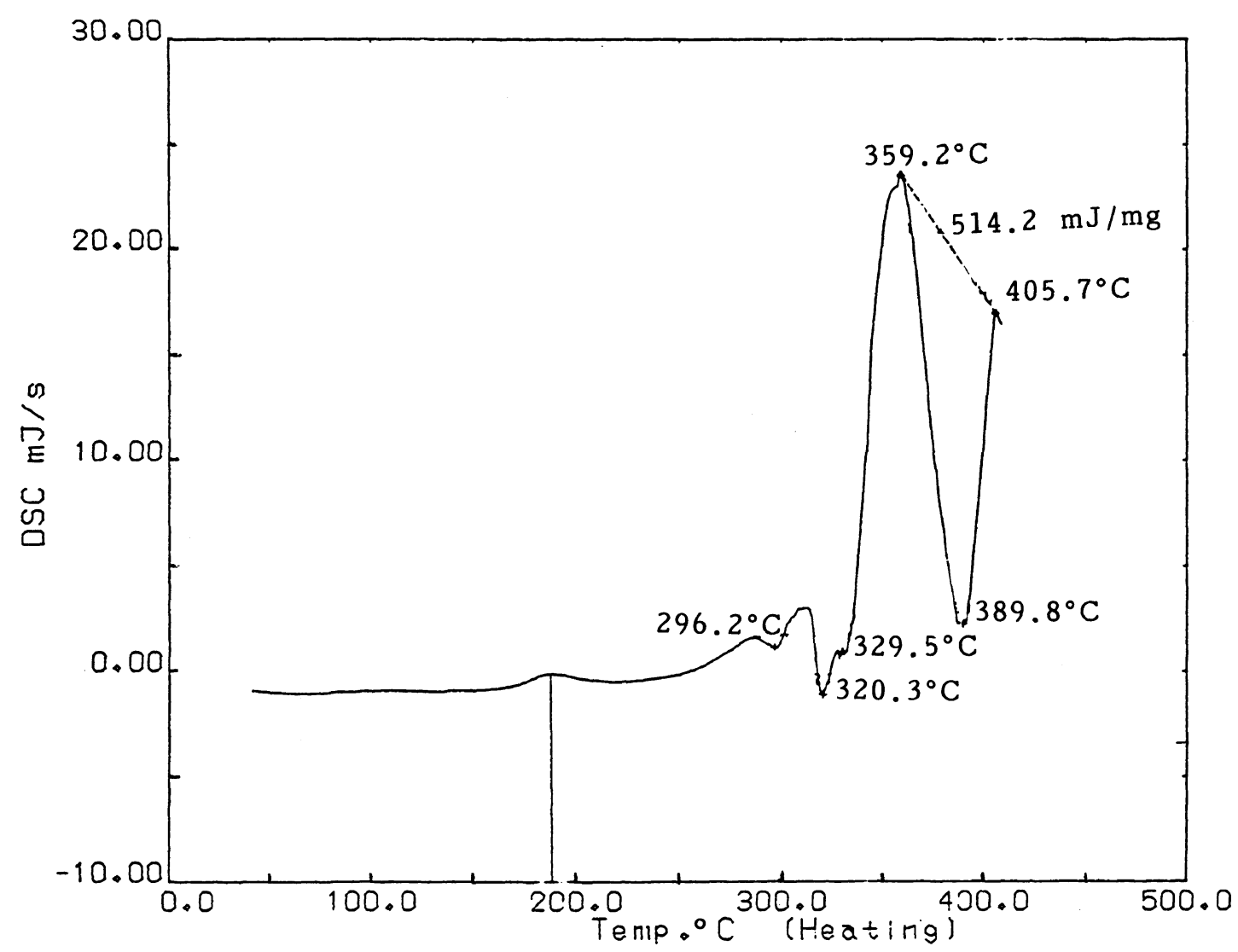

Figure 2. DSC curve of poly-DL-phenylalanine. Progress rate, $5^{\circ} \mathrm{C} / \mathrm{min}$.
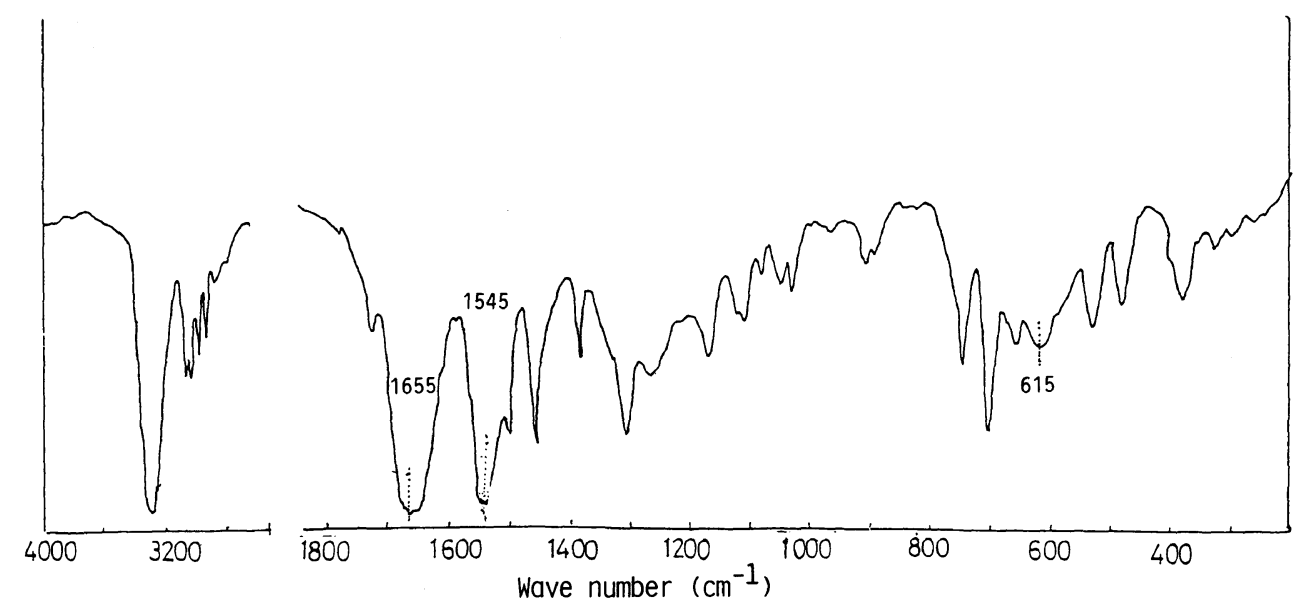

Figure 3. Infrared spectrum of the copolypeptide of L-alanine with L-phenylalanine $(50: 50)$.

(Amide II), 615, 535, 515, 480, and $490 \mathrm{~cm}^{-1}$, form in dichloroethane. Copolypeptides conindicating that the copolypeptides takes a sisting of Phe with L-alanine (Ala) (No. 2) mixed conformation of $\alpha, \beta$, and coiled or $\alpha$-amino $n$-butyric acid (n-BA) (No. 3), 
were insoluble in dichloroethane and benzene as polymerization solvents at a room and a high temperature.

The infrared spectrum of the system of copolypeptide gel No. 4 (Phe- $n$-Val; 50:50) showed the bands due to the polypeptide in the mixture of $\alpha, \beta$, and coiled forms. This gel swelled much in displacing the three-forth polymerization solvent of dichloroethane with benzene. The infrared spectrum of the system including swollen copolypeptide No. 4 showed the bands due to the polypeptide in $\alpha$-helix and small amount of coiled forms. The gel of No. 5 (Phe- $n$-Leu; 50:50) showed absorptions at $1720,1690,1658,1545$, and $1520 \mathrm{~cm}^{-1}$. Characteristic of $\beta$ and a small degree of $\alpha$ conformations of polypeptides. This gel also swelled out displacing the polymerization solvent, dichloroethane, with benzene, but it was slightly soluble in benzene. This insoluble polymer in benzene, after drying, showed strong absorptions at 1720,1635 , and $1525 \mathrm{~cm}^{-1}$, and weak absorptions at 1655 and $1545 \mathrm{~cm}^{-1}$ due to principal $\beta$ conformation. This suggests that copolypeptide No. 4 becomes rich in $\alpha$-conformation by replacing benzene from dichloroethane as the solvent and also drying, while No. 5 does not change conformation by the same treatment as for No. 4.

Leu NCA polymerized in dichloroethane to produce poly(Leu) with $\alpha$-conformation in the gelatinous form. This gel could not be dissolved by heating or by addition of a large quantity of an aprotic solvent. The copolymerization system of copolypeptides of Phe with L-leucine (Leu), No. 6 (Phe-Leu; 75:25), No. 7 (Phe-Leu; 50:50) and No. 8 (Phe-Leu; 25:75) gave slurry, slightly opaque or opaque gels. These gels became soluble by addition of one volume of benzene to the gel or by heating. Moffit parameter $b_{0}$ of copolypeptide No. 7 thus obtained was -530 in the mixed solvent of dichloroethane with benzene in a ratio $1: 1$, which corresponded to a helix content of $80 \%$. Copolymerization systems No. 9 (Phe-Leu; $67: 33$ ), No. 10 (Phe-Leu; 50:50), and No. 11
(Phe-Leu; 33:67) in benzene gave precipitation, colloidal solution and gelatinous form, respectively. Values of $b_{0}$ of the solution of No. 10 and 11 were -440 and +1200 respectively. Infrared spectra of systems No. 10, 11 and of poly $(\mathrm{L}-\mathrm{leu})$ in benzene show the absorptions at $1655,1650,1545,1527,480$, and 400 , at 1652 , $1650,1547,1525,475$, and 400 , and at 1655 , $1650,1620,1540,1520,480$, and $400 \mathrm{~cm}^{-1}$, respectively. These results indicate that the systems No. 11 and the poly(Leu) both of which formed gel take $\alpha, \beta$, and coiled conformation of copolypeptides, and No. 10 in which is colloidal solution was included coiled and $\alpha$ conformational copolypeptide.

The main chain of copolypeptides containing DL-Phe residues is in a more random than those containing L-Phe residue only. However, results showed that the helicity of copolypeptides containing L-Leu, L-Phe and DL-Phe (No. 12,13 , and 14) was not always less than those of copolypeptides containing all corresponding L-amino acids only (No. 6, 7, 8, 9, 10, 11) and strongly depended on the content of Lleucine residue.

We previously reported that copolypeptides of DL-alanine with $\beta$-benzyl L-asparatate (OBzlAsp) were less soluble than those of all corresponding L-amino acid only, inspite of the fact that the main chain of copolypeptides containing DL-amino acid residues took a more random conformation than those containing L-amino acid only. ${ }^{3}$ However, the copolypeptides containing DL-phenylalanine residue (No. 12, 13, and 14) was almost same as that containing $\mathrm{L}-\mathrm{Phe}$ corresponding ratios (No. 6, 7, and 8).

Infrared spectra of copolypeptide No. 9 (Phe-D-Phe-Leu; 67:9:24) had absorptions at 1660 and $620 \mathrm{~cm}^{-1}$, ascribable the $\alpha$-conformation, and 1650 and $700 \mathrm{~cm}^{-1}$ due to coiled conformation. This suggests that copolypeptide of Phe with Leu containing Phe ranging in content from 25 to $50 \%$ was more soluble than poly(Phe) or poly(Leu).

It has been reported that $\gamma$-benzyl L-glu- 
tamate (OBzlGlu) NCA polymerized in aprotic solvents such as dioxane and tetrahydrofuran in a homogeneous system produces high molecular weight poly(OBzlGlu) with helical conformation. $^{9-11}$ Copolymerization system No. 16 (Phe-OBzlGlu; 10:90), 17 (PheOBzlGlu; 25:75), and 18 (Phe-OBzlGlu; $50: 50$ ) having a moffit parameter $b_{0}$ of -570 , 560 , and -240 which corresponded to a helix content 90,89 , and $38 \%$ respectively, were in the solutions after the polymerization. The moffit parameter $b_{0}$ siginificantly decreased by increasing the content of L-Phe residue in the copolymers (No. 16, 17, 18). The conformations of these copolymers obtained by ORD measurement agreed with that obtained by IR spectra in the polymerization system. These also may indicate that the interaction between the solvent and phenyl side chain in the copolymer destroys helix conformation of the copolypeptides. Infrared spectra of these copolypeptides showed strong absorption at 1660 and $615 \mathrm{~cm}^{-1}$ due to the $\alpha$-conformation by drying. The conformtion was transformed to the $\alpha$ by isolation of the solvent. In addition, No. 18 gave absorption at $1635 \mathrm{~cm}^{-1}$ due to the $\beta$-conformation. The $\alpha$-helix content of copolypeptides of OBzlGlu and Phe, and OBzlAsp and L-Phe depend on the ratio of amino acid residues decreased by increase in the Phe content in dichloroethane $(16-18$, and $20-21$ ), and was less than those of copolypeptides OBzlGlu and Leu, and OBzlAsp and Leu at the corresponding ratios.

Copolypeptides of OMeGlu with Phe were obtained in a colloidal solution in dichloroethane (No. 24-27). The moffit parameter $b_{0}$ was obtainable for No. 24 and No. 27. The infrared spectra of these copolypeptides in the colloidal solutions showed bands at $1660(\alpha), 1650(\beta$ or colil), 548w $(\alpha$ ?), and $488 \mathrm{w}(\beta) \mathrm{cm}^{-1}$. For No. 26, the bands due to a mixture of $\alpha$ and $\beta$ for No. 27 and 28 .

Copolymer of OBzlAsp with $\varepsilon$-carbobenzoxy L-lysine (ZLys) in the ratio of 50:50 has been known to be soluble in many aprotic solvents such as dichloroethane, dichloroethane, acetonitrile and benzene. ${ }^{3}$ The solution of copolypeptide of OBzlAsp with ZLys in a ratio of $1: 1$ had a moffit parameter $b_{0}$ of -595 in dichloroethane. Copolypeptide No. 31 (OBzlASp-Zlys-Ala; 23:48:29) was soluble in dichloroethane. This solution had $b_{0}$ of -580 , which correponded to a helix content of $90 \%$. Copolypeptide No. 30 (OBzlAspPhe-Zlys; 29:23:48) was also soluble in dichloroethane which solution had $b_{0}$ of -65 due to $\alpha$ helix content of $11 \%$. This indicates that Phe residue destroys the helix conformation in the copolypeptides in aprotic solvents in the same way as copoly(OBzlGlu, Phe) and copoly(OMeGlu, Phe). The, Ala residue did not destroy the helix conformation of copolypeptide No. 25 (Ala-OBzlAsp-ZLys; $29: 23: 48$ ) which had component as phe residue in copolypeptide No. 24. These results show that the solubility of polypeptides containing phenylalanine is easily affected by the configuration.

The solubility affected by the side chains of the polypeptides may be as follows. When

Table II. Permeability of water vapor of copolypeptide films ${ }^{\mathrm{a}}$

\begin{tabular}{rlc}
\hline No. & Component & $\begin{array}{c}\text { Permeability } \\
\text { of vapor } \\
\left(\mathrm{g} \mathrm{m}^{-2} \cdot 24 \mathrm{~h}\right)\end{array}$ \\
\hline 1 & OEtGlu-Leu; $1: 1$ & $2200^{\mathrm{a}}$ \\
2 & OEtGlu-Leu; $2: 1$ & $2300^{\mathrm{a}}$ \\
3 & OEtGlu-Phe-Leu; $1: 1: 1$ & $2000^{\mathrm{a}}$ \\
4 & OMeGlu-EtGlu; $4: 1$ & $2700^{\mathrm{a}}$ \\
5 & OMeGlu-EtGlu-Leu; $8: 1: 1$ & $2000^{\mathrm{a}}$ \\
6 & OMeGlu-Leu-Phe; $63: 17: 20$ & $1900^{\mathrm{a}}$ \\
7 & OBzlAsp-Ala-Phe; $29: 23: 48$ & $450^{\mathrm{a}}$ \\
8 & OEtGlu-Phe; $71: 29$ & $3800^{\mathrm{a}}$ \\
9 & OBzlAsp-ZLys-Ala; $29: 23: 48$ & $250^{\mathrm{a}}$ \\
10 & OMeGlu-Leu; $1: 1$ & $3700^{\mathrm{b}}$ \\
11 & OMeGlu-Leu-Phe; $2: 1: 1$ & $4400^{\mathrm{b}}$ \\
12 & Leu-Phe; $3: 1$ & $5000^{\mathrm{b}}$ \\
13 & OEtGlu-Phe; $71: 29$ & $5000^{\mathrm{b}}$ \\
14 & OMeGlu & $4800^{\mathrm{b} . \mathrm{c}}$
\end{tabular}

a Thick, a; 15, b; $10 \mathrm{~m}$. micron, c; Ajicoat (Ajinomoto Co.). 
poly(Phe) has a helix formation the polymer is insoluble in many aprotic solvents because of the stronger interaction of phenyl residues of the side chain than that between phenyl residue and solvent. When the phenyl residue of the side chain in the copolypeptides decreased, the solubility of the copolypeptides in the aprotic solvents increases because of the decrease in the degree of intermolecular interaction between the phenyl residues, and increase in the solvation of the phenyl residue with the solvent.

The permeability of water vapor of the copolypeptide films was measured in order to see whether the dependency of the permeability on the hydrophobic pendant group (Phe) could be observed or not (Table II). No correlation was observed between them.

Acknowlegments. We wish to thank Dr. Iwakura of Seikei University and Dr. Hayashi of Kyoto University for useful advice, and also Mr. Iwatuki, Mr. Honma, and $\mathrm{Mr}$. Kayama, Ajinomoto Company for measurement of the permability of water vapor and Mr. Asano and Dr. Kaetsu of Takasaki Radiation Chemistry Reserch Development for mesurement of differental scanning calorimetry.

The present work was partially supported by a Grant-in-Aid for Scientific Research (No. 61490008) from the Ministry of Education, Science, and Culture of Japan.

\section{REFERENCES}

1. R. B. Woodward and C. H. Schramm, J. Am. Chem. Soc., 69, 1551 (1947).

2. E. Katchalski and M. Sela, "Advance in Protein Chemistry," Vol. 13, Academic Press, New York, N. Y., 1958, pp 438-455.

3. M. Oya and H. Kyotani, Polym. J., 18, 513 (1986).

4. M. Oya and R. Katakai, "Shin Jikken Kagaku Koza, Vol. 19-1; Polypeptides," Nippon Kagaku Kai, Ed., Maruzen, Tokyo, 1978, p 144.

5. J. T. Yang, "Poly- $\alpha$-amino Acids," G. D. Fasman, Ed., Marcel Dekker, New York, N. Y., 1967, p 239.

6. J. T. Yang and P. Doty, J. Am. Chem. Soc., 79, 761 (1957).

7. K. Itoh, T. Shimanouchi, and M. Oya, Biopolymers, 7, 649 (1969).

8. K. Itoh, M. Oya, and T. Shimanouchi, Biopolymers, 11, 1137 (1972).

9. E. R. Blout and R. H. Karlson, J. Am. Chem. Soc., 78, 941 (1956).

10. M. Goodman and J. Hutchison, J. Am. Chem. Soc., 88, 3627 (1966).

11. Y. Masuda, Kobunshi Kagaku, 20, 171 (1963). 